\title{
Mergers and Acquisitions: An interface to Economic Development
}

\author{
Angi Sinha, Astha Srivastava, Anwesha Pathak
}

\begin{abstract}
Economic development is a wide aspect which gradually is one of the sole motives of any country. There are numerous ways by which they try to achieve this goal and become a powerful country among all other nations. Financial power is one such power which keeps any nation on its toes to make any powerful decisions, at any time of the day. In order to achieve such goals one of the initiative is through the corporate sectors. Corporate sectors are the one which provides higher job opportunities, chance to work and research in this field and many others. Economy of our nation is directly proportional to the sectors it deals with, so if the corporate sector grows it can act as an interface for the economic development of our nation. Now, practically corporate sector develops in two ways one is internally, i.e. by making profit or by raising their share capital. And the other one is by getting combined with other company and working together as one single entity. This combination can be termed as mergers or acquisitions, which acts as one of the major catalyst for the economic growth of our nation worldwide.
\end{abstract}

\section{INTRODUCTION}

Mergers and Acquisitions as the name suggest,are the two different terminologies but somewhere deal with the same aspects. Mergers are the combination or merging of different entities into one unit and function accordingly. Whereas, acquisition is the concept where one company acquires the other company, there assets, liabilities, shareholdings etc. and function as one huge body, however acquisition leads to the formation of no new entity. Mergers can be segregated into different types as per the market structure, for instance horizontal mergers where the mergers takes place between the companies having same level of production. Vertical mergers takes place when the companies are at different stages of production merger. Concentric merger comes into existence when the merger takes place between the company dealing with complementary and supplementary goods. One more aspect of merger is the conglomerate merger where the mergers take place between two companies dealing with entirely different production of goods and services. All these stated structures somewhere or the other let to the development of the companies organically or inorganically.

\section{METHODOLOGY}

\section{Aspect for Economic Development:-}

After going through the concept the next important question that comes up in all our minds is why any company in the corporate world wanted to get merger with any other entity and exchange their policies? One basic reason can be understood as when two entities mix up and get enlarged it

Revised Manuscript Received on 14 August, 2019.

AngiSinha, Assistant Professors, New Law College, BharatiVidyapeeth, Pune, Maharashtra, India.(Email: shivangisahay8@gmail.com)

AsthaSrivastava, Assistant Professors, New Law College, BharatiVidyapeeth, Pune (Email:srivastavastha9@gmail.com)

AnweshaPathak, Assistant Professors, New Law College, BharatiVidyapeeth, Pune (Email:pathakanwesha4@gmail.com) acts as one of the major gain of corporate finance in the world. This major gain will directly or indirectly affects the economic structure of our country. Technically, mergers or acquisitions take place when one company purchase the shares of the other company, or by purchasing assets or even exchange of shares. The main reasons for them to occur can be stated under the following heads:-

- $\quad$ Accelerating the companies profile and growth.

- $\quad$ Quantitatively and qualitatively exchange of goods and services.

- $\quad$ Route for enlarged market structure.

- Employees benefit

- Exchange of technical know-how etc.

Mergers and Acquisitions can also be named as corporate restructuring. This is because there already exist one structure, which is organically or inorganically created or structured again. Corporate restructuring have many different modes, but all the modes falls under two broad heads i.e. financial restructuring or organizational restructuring. Organizational restructuring basically includes shuffling of the employees within the organization. Financial restructuring includes advance economic benefits inside and outside the organization, which further also leads to increase in the GDP rate of the country. Different modes of corporate restructuring include forms such as amalgamation, the concept is defined under the Income Tax Act of 1961, which states that amalgamation occurs where two or more entities merge with another entity to form one big entity. Reverse merger, this is a concept where a private company purchases the control of a public company and function accordingly. Takeover is also one of the modes, where one company purchases the other one etc. For instance, Maruti Motors operating in India and Suzuki is a company based in Japan both got amalgamated and formed a new entity known as Maurti Suzuki (India) Ltd. Now, this new entity formed if observed from a wider perspective, has a broad market structure, deals with lot more technical skills and thus earns more revenue. This revenue eventually will be paid to the government (according to the tax slab), which will eventually lead to our economic development.

In the past recent years the concept of mergers and acquisitions has taken up a boost. Our government has also encouraged the concept of cross border merger, where any foreign company can also get merge with the Indian company and vice-versa. These concepts enhance the economic development directly through the concept of tax collection, and indirectly by giving a new structure to the 
market by employment generation, filling up the gaps in the market by bringing new intellectual or technical skills. For instance any company " $A$ " who is having capital to invest merge with another company "B" who have the technical know- how can fill up the gaps in the market structure and can indirectly become a cause for the revenue generation at large. Such practices can expand the business and operations of the company, can carry business more economically or efficiently, will have time to focus on their core strength and can also have a better market share.

Mergers and acquisitions is not only about giving and taking money, but is also about bringing a new business model structure altogether. This helps in bringing out many new market services such as marketing, insurance, increase the product and supply chain, eliminate unnecessary competitions from the markets etc. All these services attract many multi- national co operations to come and invest in our country, which eventually can become one of the causes of our economic development. In this context, we can quote some real life illustrations which have taken place in the recent past, for instance Sun Pharmaceuticals acquired Ranbaxy. This acquisition had many objectives, which was eventually fulfilled; both the companies filled up the market gap in US and boosted their economy by taking over the control on their market structure. Another illustration which can be taken into account is ICICI merging with ICICI Bank.

\section{FINDINGS}

Negative Aspect:-

There are always two sides of a coin in the same way the concept of Mergers and Acquisitions comes with the whole package, no matter it is one of that concept which fulfils the requirement of the concept synergy i.e, it produces a greater effect on the market and our economic enterprises after the corporate sectors are merged, rather when they were working as an individual corporate sectors. However, the first negative impact which can be taken into consideration is the variation of cultural differences. It basically means when two companies combines the employees of both the sectors also merge to work under the same head.

\section{RESULTS AND DISCUSSIONS}

The practical difference lies in the fact that the employees of both the sector initially belongs to two different working environments and culture and now after the policies have got merge they need to work together. Sometimes when the employees are not comfortable with the polices undertaken they end up quitting their jobs, this is because learning new culture at times becomes challenging. This culture differences not only stays here but at times the employees who are retained back end up having negative feeling of competitiveness [1] around them, which can turn into as an alarm for the HR departments. Consolidation of the two companies can sometimes also led to the process of layoff, which eventually affects the lives of the employees personally; at times they do not have a back up ready. This generally happens because whenever the companies' merge, they never look for having two CEO's or two HR departments etc. This is one of the negative aspects of mergers and acquisitions morally and internally.

There were many huge and big mergers which were eventually stopped from happening such as RCOM and Aircel Merger, IDFC and Shriram Finance, HDFC and Max Life etc. All these mergers were stopped by there relevant departments at some stage or the others. Although the reasons were many and critical but on the conceptual part the benefits of the markets, employees and shareholders were taken into consideration. Sometimes these consolidations of the company create a monopoly condition in the market. For instance, when two soap producing company merge it can put up any market price for the consumers and the consumers will be left with no option rather than buying them at the price quoted by them. This eventually can create a situation of monopoly in the market and there will be no entry and exit for other players in the market. This can eventually lead to the market to stagnate at certain point. Therefore, we can say that it's not necessary that the company which may profit can improve the economy as well. Thus, we have the adjudicating bodies like NCLT, NCLAT, and CCI which are governed under the Companies Act of 2013, Competition Act 2002 which analyse all the production scales and level of market situation and allow the mergers accordingly.

\section{CONCLUSION}

Thus, we can conclude that Mergers and Acquisitions of any company taking place have numerous and huge implications on the economy and public policy as well. This is one concept which covers all the sectors broadly, such as banking sector, telecom sector, corporate sectors, industrial sectors and many others. Since it involves large amount of give and take procedure and involves individuals as well as economies interest at large, so it is advisable from the company as well as from the adjudicating authorities to take the decision amicably. Mergers and Acquisitions is also considered as a process of financial due diligence. Therefore, it is always advisable for both the parties' before entering into the contract or procedure of combinations of companies to know the assets, liabilities of the each other any ongoing litigations, history and background into the project taken before and entered into, all the various types of intellectual properties coming up with the company etc. In layman's term it's just like getting into a relationship for the benefit of the society, therefore it is prudent to get into a background check and take up a rational decision, so that it turn into a beneficial concept of going forward rather than coming back.

\section{REFERENCES}

1. Srivastava, Astha. "Patent And Competition Interface: Issues And Challenges In India." Int. j. of Social Science and Economic Research, vol. 4, no. 2, Feb. 2019, pp. 1521-1527, ijsser.org/more2019.php?id=111. 
1. Sarda, M. Deshpande, B. Shringarpure, S.: "Smart city - Use of technology and the needed labor reforms", International Journal of Innovative Technology and Exploring Engineering 2018.

2. Sarda, M. Deshpande, B., Deo, S., Karanjkar, R.: “A comparative study on Maslow's theory and Indian Ashrama system", International Journal of Innovative Technology and Exploring Engineering, 2018.

3. Sarda, M., Deshpande, B., Dharm, J., Dhere, V.: "Different aspects of environmental laws", International Journal of Recent Technology and Engineering, 2019.

4. Deshpande, B., Girme, A. : "Research methods made simple", International Journal of Innovative Technology and Exploring Engineering, 2019.

5. Girme, A., Deshpande, B.: "The life line of human beings-"Right to potable water", International Journal of Recent Technology and Engineering, 2019.

6. Sinha, S. Deshpande, B., Deo, S., Vedpathak, S.: "Potential appeal mechanism by consent: Arbitration", International Journal of Recent Technology and Engineering, 2019.

7. Srivastava, A., Sinha, S.:"Cyber Delinquency: Issues and Challenges under Indian Legal System", International Journal of Engineering and Advanced Technology (IJEAT) 2019

8. Anuradha G., Revolutionary Yogic Agriculture, International Journal of Recent Technology and Engineering (IJRTE) ISSN: 2277-3878, Volume-8 Issue3, September 2019

9. Deo, S., Deo, S.: "Cybersquatting: Threat to domain name", International Journal of Innovative Technology and Exploring Engineering, 2019.

10. Deo, S., Deo, S.: "Domain name and its protection in India", International Journal of Recent Technology and Engineering, 2019.

11. Dubey, R., Sakhalkar, U.: "A critical analysis of rising intolerance and growing polarisation: Lynching”, Journal of International Pharmaceutical Research, 2019.

12. Ujjwala Sakhalkar, Community Participation for access to Justice to children: A road map for future, International Journal of Recent Technology and Engineering,2019.

13. Salil Shringarpure, Internet Trolling: Analyzing the legal myths and facts, International Journal of Engineering and Advanced Technology, 2019.

14. Shaikh, A., Khandare, J.: "International parental child abduction in United States of America and India", International Journal of Engineering and Advanced Technology, 2019.

15. Khandare, J., Shaikh, A.: "When life becomes death: A stifling story of air pollution", Journal of International Pharmaceutical Research, 2019

16. Pathak, A. Mishra, A.: "Human trafficking in India", Journal of International Pharmaceutical Research, 2019

17. Bendale, U., Dhere, V.: "Right of aged persons to live with dignity: A socio-legal perspective", International Journal of Innovative Technology and Exploring Engineering, 2019

18. Dhere, V., Bendale, U.: "Impact of smart city on social relations", International Journal of Innovative Technology and Exploring Engineering, 2019.

19. SukrutDeo and Dr. SapnaDeo, "Cybersquatting: Threat to Domain Name", International Journal of Innovative Technology and Exploring Engineering, 2019

20. Srivastava, A. Sinha, S.: "Anti dumping policy and its effect on indian pharmaceutical sector ",International Journal of Engineering and Advanced Technology, 2019. 